\title{
PARA UMA POÉTICA DA DEMARCAÇÃO: EMA, DE MARIA TERESA HORTA
}

\author{
Sarah Carmo \\ Université Sorbonne Nouvelle - Paris 3 (CREPAL)
}

\section{RESUMO}

Neste estudo, propomos analisar a inscrição do género no romance de Maria Teresa Horta, Ema. Partindo da expressão "marca do feminino" oriunda do campo da gramática, estudamos a forma como esta marca se institui enquanto lugar de uma demarcação. Observamos, num primeiro passo, o processo de demarcação praticado pelo masculino sobre o feminino. De facto, na própria letra do texto, o masculino vem imprimir a sua marca no feminino, opondo-se a ele e apagando-o. Numa segunda parte, debruçamo-nos sobre as estratégias elaboradas pelo feminino na tentativa de se demarcar, isto é, para legitimar e impor a sua diferença. Finalmente, numa última parte, analisamos a forma como o feminino origina e desenvolve a demarcação enquanto fronteira ou limiar que, ao mesmo tempo que separa, permite o encontro e os movimentos de passagem e transição.

PALAVRAS-CHAVE: demarcação, género, Maria Teresa Horta.

\section{ABSTRACT}

This study aims to analyze the functioning of gender in the discourse of Maria Teresa Horta's novel Ema. Taking up the expression "the mark of the feminine" (gender) used in Portuguese grammar, I attempt to demonstrate how this mark becomes instituted in Ema as the site of a demarcation. As a first step, I analyze the "de-marking", or unmarking, operation performed by the masculine upon the feminine. In fact, the masculine functions in the novel's discourse as that which imprints its mark, opposing and suppressing the feminine. In the second part, I examine the strategies of demarcation deployed by the feminine to impose and legitimize its difference. Finally, I consider the ways in which the feminine operates the demarcation as a border or threshold that, while separating, also and primarily allows for the encounter and the movement of passage or transition.

KEYWORDS: demarcation, gender, Maria Teresa Horta. 
NE PAS MELER les genres. Je ne mêlerai pas les genres. Je répète: ne pas mêler les genres. Je ne le ferai pas. (DERRIDA, 1986, p. 251)

Esta epígrafe, tirada de "La loi du genre" de Derrida, soa como um interdito que não se deve transpor. Segundo o mesmo, este interdito habita a noção de género que instaura, quando convocada, um limite, uma separação, uma demarcação que opõe, entre outros exemplos, homem e animal, natureza e cultura, homem e mulher. $\mathrm{O}$ género remete assim para uma taxinomia, um sistema de classes que reúne em conjunto indivíduos com traços identificáveis e semelhantes. Introduz uma norma que se deve respeitar para não arriscar a contaminação, a mistura, a monstruosidade. Esta é a lei do género. No entanto, segundo Derrida, a pureza essencial do género, inscrita na sua lei, só é possibilitada pela existência de uma contra-lei: a lei da lei do género.

C’est précisément un principe de contamination, une loi d'impureté, une économie du parasite. (...) je parlerais d'une sorte de participation sans appartenance. Le trait qui marque l'appartenance s'y divise immanquablement, la bordure de l'ensemble vient à former par invagination une poche interne plus grande que le tout, les conséquences de cette division et de ce débordement restant aussi singulières qu'illimitables. (DERRIDA, 1986, p. 256)

Afirmando desta forma a necessidade da contaminação, Derrida coloca de novo em questão o género, considerado então como transbordamento em constante geração, como renovação dos limites. A ideia de "participação sem pertença" pratica uma abertura, possibilitando de igual modo a passagem e a transgressão, o que impede qualquer forma de clausura. A obra de Maria Teresa Horta, frequentemente distinguida pela sua energia transgressiva, prende-se precisamente com essa dinâmica que faz do género algo mais do que uma estrita taxinomia, nomeadamente no que diz respeito à relação entre o feminino e o masculino. Na sua obra, a questão do feminino, longe de se reduzir às marcas supostamente definidoras de uma classe de pertença, participa de um movimento de desestabilização das categorias. Desse modo, a sua poesia surge naturalmente como o lugar privilegiado onde, e a partir de onde a expansão do feminino se dá. Porém, observamos que em muitos dos textos de ficção de Maria Teresa Horta, a lei do género retoma os seus direitos mantendo bem viva a oposição entre o masculino e o feminino como modo de representação e denúncia das violências infligidas às mulheres. O nosso intuito será analisar a forma como a obra de Maria Teresa Horta é trabalhada pela demarcação, que também 
é desmarcação e "re-marquação". A partir do romance Ema que constitui, segundo nós, um marco central na produção da autora, estudaremos a forma como o masculino impõe a demarcação no sentido duma separação e duma anulação do feminino para, em seguida, analisar a réplica do feminino na sua tentativa para deslocar os marcos e fazer da demarcação uma passagem e um encontro.

O romance Ema retrata o quotidiano angustiante de três mulheres, avó, mãe e filha que, ao partilharem o mesmo nome, partilham também a mesma sujeição ao marido e ao pai. Constantemente violentadas, essas mulheres são descritas como seres que não podem assumir a sua identidade e que devem obedecer à vontade do homem. Por isso, feminino e masculino encontram-se separados. Este facto manifesta-se precisamente no jogo dos pronomes como, por exemplo, o escasso uso da primeira pessoa do plural que, quando surge, não remete para o casal. Da mesma forma, em certos passos do texto, os pronomes entram em conflito e testemunham da violência das relações conjugais: "tu me bateste me atirando sobre a cama" (HORTA, 1985, p. 50). O emprego da próclise, contrária à norma portuguesa, tal como o uso de um pronome sujeito dispensável, vêm colocar frente a frente os pronomes da primeira e da segunda pessoa para melhor salientar a impossível união. A demarcação vem então delimitar dois espaços incomunicáveis: o do homem e o da mulher que se encontram recolhidos nas suas solidões. Ema, desolada, imagina o que seria o quotidiano do seu marido sem ela: "imagina (...) a pressa constante nos gestos, a correr para as reuniões, os cadernos, os livros; a pensar em tudo isso mesmo enquanto janta, calado, ausente." (HORTA, 1985, p. 68). O uso do pronome "isso", síntese de todos os elementos que compõem o quotidiano do marido, realça o distanciamento de Ema em relação ao universo masculino do qual é excluída a mulher.

Essa demarcação, desejada e assumida pelo homem, revela então a clausura da mulher, que também é cláusula. De facto, as três Emas devem responder a uma série de prescrições, de leis, que se impõem como formas de encerrá-las num papel predefinido, tido por natural. De igual modo, a mãe torna-se cúmplice desse sistema ao transmitir pela educação as leis que delimitam o género feminino. Durante a infância, Ema deve seguir os ensinamentos da mãe - "Menina em casa de seu pai obedece. Como mulher deverá um dia obedecer em casa de seu marido!” (HORTA, 1985, p. 38); "Uma mulher põe os olhos no chão, não olha para os lados" (HORTA, 1985, p. 73). E já casada, deve obedecer ao marido: “- A ti devem-te é interessar os vestidos. Deixa os livros para mim” (HORTA, 1985, p. 39); “- Pró́bo-a que leia!” (HORTA, 1985, p. 104)

A reiteração destas regras condicionam o relacionamento entre, num primeiro momento, a mãe e a filha, e num segundo momento, entre marido e mulher, colocando esta última num lugar de inferioridade. Introduzida dessa forma numa relação que deveria ser de afecto, a lei acentua a separação e impede até os laços entre mãe e filho de se desenvolverem. 
Assim, a gravidez é vivida como uma tortura sofrida do interior do corpo: "Será assim toda a gravidez como se quisesse deitar o feto pela boca." (HORTA, 1985, p. 24). Mais longe, a segunda Ema, sentindo-se culpada por não ter dado à luz um menino, não consegue aceitar a filha que a vida lhe deu: "Mas a menina não se calava nunca e Ema ao terceiro dia acabou por lhe estender o peito, ao comprido na cama, de lado, metendo-lhe apenas o bico castanho do seio na boca escancarada de choro." (HORTA, 1985, p. 118). O ideal do instinto maternal é aqui deitado abaixo. A ligação que o gesto de amamentar deveria estabelecer é negada pela distância que Ema mantém perante a sua filha. Com efeito, Ema consente-lhe apenas uma extremidade do seu corpo que parece quase despegada de si, como o sugere a própria construção da frase que, ao multiplicar os complementos circunstanciais e as perífrases, reduplica a sensação de afastamento. Ema, enquanto mãe e origem, rompe portanto com uma genealogia da qual, no entanto, é excluída porque só pode ser masculina. De facto, ao relembrar a necessidade de conceber um "filho varão, herdeiro de honras e de nome" (HORTA, 1985, p. 77), Ema indica que jamais o filho poderá ser seu. De facto, o nome do pai substitui-se à ligação maternal numa tentativa de negá-la, como o entende Luce Irigaray: "quand le nom propre est donné à l'enfant, il se substitue déjà à la marque la plus irréductible de la naissance : le nombril." (IRIGARAY, 1987, p. 26). O nome do pai corresponde, por conseguinte, a uma violência exercida sobre a mulher na afirmação da sua diferença, e funciona portanto como um modo potente de apagar o seu rasto, o seu lugar na filiação, a sua marca.

As três Emas estão assim condenadas à impossibilidade de ser, visto que são separadas de tudo aquilo que poderia constituir a sua identidade: livros, homem, família. De facto, vão sofrendo um apagamento constante das marcas a partir das quais poderiam sustentar o ser. A começar pelo nome. Durante uma das suas sessões de terapia, a terceira Ema relata o episódio da sua nascença em que a baptizaram: "Deram-me o nome de Ema como o de minha avó: mãe de que mãe? estive a morrer, sabe? estive a morrer à nascença. Baptizaram-me à pressa e deram-me o nome de Ema” (HORTA, 1985, p. 13). Nomear é identificar, mas é também pôr uma marca, classificar, segundo Derrida. "Nommer, donner les noms (...) telle est la violence originaire du langage qui consiste à inscrire dans une différence, à classer, à suspendre le vocatif absolu" (DERRIDA, 1967, p. 164). Revela-se aqui a ambiguidade do nome. Se, por um lado, o nome parece instituir uma genealogia feminina ao ser transmitido de mãe para filha, como aliás o sugere o anagrama Ema/mãe, por outro lado, a intromissão da terceira pessoa do plural faz ouvir a voz de uma autoridade superior e anónima que desactualiza a origem do nome e desfaz essa mesma genealogia. Afinal, a criança é reduzida à sua condição feminina da qual não pode fugir. $\mathrm{O}$ nome Ema, repetidamente atribuído, torna-se comum, e passa a designar a mulher em geral, espécie de Eva que teria perdido o V vaginal, substituído pelo $\mathrm{M}$ masculino, a marcar a posse. 
Em reacção a esta dominação, Ema enceta um processo crescente de apagamento, que resulta também de uma imposição pessoal: a de nunca deixar nenhuma marca, nenhum rasto, como o confessa a terceira Ema, iniciando assim a des-marcação: "É isso: tenho vivido toda a vida como se tivesse cometido um crime, a limpar todas as minhas impressões digitais." (HORTA, 1985, p. 81). De forma semelhante, a repetição, ao longo do texto, da descrição de Ema numa cadeira de baloiço insiste neste apagar das marcas ao mesmo tempo que impõe ao relato o vaivém deste mesmo baloiço que nunca se inscreve num lugar, porque em constante movimento:

Ela olha em frente, sentada na cadeira de balouço: palhinha e madeira baça, lisa, onde passeia os dedos a deslizarem suaves; as unhas levemente a arranharem, só no gesto brando, prudente, não vá ficar alguma marca.

"Prudentemente. Não vá ficar alguma marca da tua passagem por aqui. Algum vestígio."

- Ema. (HORTA, 1985, p. 11).

À promessa interior, acrescenta-se um vocativo que interpela a protagonista e que vem acentuar a sua "desinscrição" por aparecer num contexto enunciativo nulo, isto é, sem enunciador identificado, e sem lugar nem tempo. Não se sabe se a repetição desse trecho remete para um episódio acontecido uma só vez ou variadas vezes, nem qual das três Emas é aqui chamada. O nome parece voar. Da mesma forma, a transcrição das sessões de terapia seguida pela terceira Ema prende-se com uma igual vontade de reproduzir uma voz desencarnada. Os parenteses que enquadram esses episódios extraem-nos da restante narração e do desencadear linear dos eventos. O discurso da análise destaca-se (demarca-se), fazendo da introspecção o lugar da interrogação dos papéis estabelecidos e dos significados rígidos; lugar da renovação das marcas : "(Sonho noites a fio:/ o meu cabelo é uma asa. Parece uma asa quando move; dançando?)” (HORTA, 1985, p. 24). Recorrendo ao sonho e retomando o símbolo da asa, ${ }^{2}$ a protagonista revela a sua recusa dos limites e reivindica a capacidade, expressada por H. Cixous, "de brouiller l'ordre de l'espace, de le désorienter, de changer de place les meubles, les choses, les valeurs, de faires des casses, de vider les structures, de chambouler le propre" (CIXOUS, 1975, p. 49).

A terapia aparece como o resultado de um processo empreendido quanto antes. À violência da demarcação imposta pelo marido, a terceira Ema replica com a violência da re-marcação que pratica constantemente, deslocando os marcos que delimitavam os géneros, e invertendo os papéis. Ao negar-se a sofrer a mesma morte que a sua avó e a sua mãe - "eu recusei-me a viver a mesma morte" (HORTA, 1985, p. 116) -, Ema afirma uma identidade que não seja repetição do mesmo e que permite o reencontro com e no outro. A travessia das fronteiras começa então com a literatura porque Ema, antes de mais, é poEma. ${ }^{3}$ Ela teima em ler apesar do interdito, Eva comendo o fruto proibido. Penetrando no escritório, Ema comete uma infracção pois invade o espaço masculino, para resgatar o livro e incorporá-lo ao domínio do feminino: "enquanto fingia que bordava escondia o livro 
entre a toalha as linhas e as saias se ele se encontrava em casa." (HORTA, 1985, p. 104). Só assim o gesto de Penélope torna-se aceitável.

Da mesma forma, Ema teima em ligar-se com a mãe que tanto a rejeitou, e da qual o patriarcado tanto trabalho se dera para a separar. O texto perfila então lembranças da infância que visam valorizar a mãe e reatar um contacto carnal. Na banheira, é o sabor da mãe que surge ao de leve: “Sabe à mãe?/ Sabe à mãe: comê-la?" (HORTA, 1985, p. 29). Ema consegue ascender, graças ao gosto, a um conhecimento primordial da mãe, um conhecimento mais intuitivo, mais espontâneo do que reflectido, que permitiria a reunificação antes do parto, antes da separação, antes da ferida da diferença. A valorização da mãe deve-se assim ao sentido do sabor que lhe confere uma corporeidade, estabelecendo uma intimidade entre as duas mulheres, esse "corps-à-corps avec la mère" de que falava Luce Irigaray (IRIGARAY, 1987, p. 19). Ao sabor da mãe contrapõe-se então o saber racional do homem. $\mathrm{O}$ confronte entre as palavras sabor e saber, que possuem uma etimologia comum, acentua o antagonismo entre a relação maternal e a relação com o marido. Esta última relação assenta sobre um saber tido por intrusivo, inquisitorial, que remete para o poder: "Ele sabe de tudo' - pensa./ Sabe tudo" (HORTA, 1985, p. 23). Aqui a repetição do verbo saber é angustiante porque faz deslizar o sentido dum saber pontual, relativo ao adultério que Ema cometeu, para um saber geral que invade a protagonista sem o seu consentimento, minorando a sua capacidade de intervenção. Ao contrário deste, o sabor da mãe é totalmente desejado e procurado. Graças a esse sabor, Ema consegue tomar consciência do seu próprio corpo, detentor também de um sabor:

Quando era muito pequena imaginava antes que seria bom a mãe engoli-la a ela para ficar descansada e quente na sua barriga.

Um dia a mãe dissera a beijá-la muito e rindo: "Vou comer-te toda". E Ema sentira um arrepio longo de prazer por todo o corpo. (HORTA, 1985, p. 29)

Assim, a relação permite um deslize constante entre o corpo da filha e o corpo da mãe, e que desemboca nas primeiras experiências de prazer da menina. Não é por acaso que essas reminiscências surgem logo depois de uma cena de masturbação que encontra então as suas origens na mais inocente das experiências, esta última funcionando de resto como um acordar ao sentimento da sensação e à intercorporeidade. Segundo o ensaísta Michel Collot, "[c]'est grâce à notre commune appartenance à une même chair, qui est celle du monde, que je peux communiquer avec autrui" (COLLOT, 2009, p. 31). É dessa intuição de pertencer ao corpo-cosmos que partem muitas das personagens de Maria Teresa Horta. Por isso, são muito atentas ao tacto e ao gosto, que é uma espécie de tacto localizado na boca, abertura que permite a passagem entre o interior e o exterior. E a pele, longe de representar uma barreira entre o eu e o outro, aparece como a demarcação que permite a ligação e o contacto, fazendo do corpo um elemento sentido e sentindo. 
Daí a importância do erotismo que permite a in-interrupção, numa fusão com o outro. Ema, infeliz no seu casamento, procura no adultério uma forma de chegar a essa intercorporeidade; em vão. No entanto, ao revelar esse relacionamento ao seu marido numa carta anónima, Ema inventa os elementos duma partilha mútua dos corpos: "A nudez, a minha nudez, a nudez do meu amante, ancas leves e estreitas com o tom dourado da pele dos homens arranjados./ Doce” (HORTA, 1985, p. 71). A pulsação rítmica da frase metaforiza o movimento dum deslizar suave que vai de Ema ao amante, graças à escansão da palavra nudez introduzida sempre com uma pequena variação, partindo assim dum conceito geral, como o sugere o artigo definido, para logo se declinar unilateralmente nos corpos dos amantes até os abarcar no entrelaçar dos corpos amorosos. Ema retoma então um tópico do corpo feminino para desenhar o corpo do homem: "As ancas" que na sua estreiteza sugerem a fragilidade do corpo nu que se dá. É desta forma que a comunhão pode acontecer; e a menção do sabor doce, realçada pela mudança de linha, faz passar os sentidos do olhar ao gosto numa sinestesia que apaga os limites corporais da pele e da boca.

Esse erotismo que se caracteriza por uma geografia corporal faz de cada parte do corpo uma etapa, um marco sobre o qual se detém o olhar e incita ao percurso. Já nas festas de Natal, as três Emas tentam subjugar o olhar dos convidados para provocar neles uma fascinação que será ao mesmo tempo uma forma de tocar:

Mas ela expõe-se. Gosta de se expor assim nua debaixo do cetim macio do vestido justo. O enorme decote, os braços despidos, as pernas magras forçando as rachas a começarem no topo das coxas.

Sente os olhos poisados nas suas coxas, nos seus braços, no seu peito. (HORTA, 1985, p. 32)

Neste trecho, a racha e o decote escondem mais do que mostram, fazendo da borda do vestido o horizonte do desejo que dá para imaginar. $\mathrm{O}$ verbo "poisar" figura bem essa quebra da distância empreendida pelo olhar que desliza sobre todas as partes do corpo. Da mesma forma, a relação íntima com o amante, no sentido daquele que se ama, implica uma descoberta do corpo do outro, atenta a todos os seus elementos. Ema, no seu banho, sonha na possibilidade de uma relação íntima com o seu marido:

Os joelhos erguem-se a pingar, afastam-se e ela começaria com os dedos dele presos nos seus a acariciar-se. Mais depressa cada vez mais depressa. Até ao fim.

Adormecera dentro da água morna já e sonha com o seu próprio corpo tomado pelo corpo dele: os artelhos, os pés, os flancos, o púbis, o umbigo, a cintura, as coxas, o pescoço, a vagina, os pulsos, o clítoris, o útero, as axilas, os joelhos, a menstruação:

Ema. (HORTA, 1985, p. 64-65).

O uso do condicional insiste sobre o carácter irreal da cena que efectivamente contrasta, e muito, com as cenas de sexualidade anterior- 
mente descritas. De facto, as relações sexuais com o marido limitam-se à penetração como forma de o homem impor a sua virilidade à mulher, "enorme, monstruoso, a abrir-me, o corpo, a rasgar-me a barriga, a matar-me como então supus." (HORTA, 1985, p. 17). Enquanto que nesse trecho a relação sexual é vivida como aniquilação do outro, o trecho anteriormente citado leva em consideração o corpo na sua totalidade, incluindo até elementos como "o artelho", "as axilas", ou ainda "os joelhos" que não são geralmente erotizados. Esta enumeração cria então um deslocamento no código da sexualidade e provoca um desmembramento do corpo que põe em causa a sua estrutura normal e que determina uma desorganização, uma desorientação propícia à descoberta de novos territórios e à contaminação dos corpos. De facto, ao mencionar partes do corpo que não são marcadas sexualmente, Ema pode muito bem evocar o corpo do marido incorporado no dela; este último acabará assim por adquirir uma componente feminina, ultrapassando a distinção dos géneros. De resto, ao imaginar-se guiando a mão do marido, Ema assume-se como sujeito activo da sua sexualidade e do seu desejo, invertendo portanto os papéis tradicionais de género que reduzem a mulher a um objecto passivo de contemplação para o homem. ${ }^{4}$

O nome, realçado novamente pelo encavalgamento e a mancha gráfica, surge como uma reafirmação da protagonista que, ao finalizar a cena, acaba também com o poder masculino, determinando o poder da mulher como agente activo. Além do mais, prosseguindo com o processo de "desinscrição" acima analisado, a presença do vocativo confere uma dimensão aérea ao corpo que não se pode reduzir ao seu carácter meramente carnal. Essa voz relembra também as outras vozes que, segundo Ema, as mulheres têm ouvido: "Já reparou que são sobretudo as mulheres que ao longo dos tempos têm escutado vozes?” (HORTA, 1985, p. 106).

Porém, essas vozes são também ligadas à loucura que Ema experimenta, por exemplo, enquanto excesso e transbordo. O cume dessa loucura acontece quando Ema mata o marido com a faca de cortar livros. Todavia, não deve ser entendida somente como um acto irracional, mas como aquilo que permite ultrapassar os opostos e pulverizar a contradição das paixões. O assassínio do marido não se assimila apenas a um gesto de vingança ou de ódio que, no entanto, Ema reivindica: "sabe qual era a minha fecundidade? o ódio" (HORTA, 1985, p. 34). É também um gesto de amor, pois aparece como necessário no sentido de anular os valores que impedem o reencontro dos amantes: "Sente o gume da lâmina entrar na carne e enterrar-se obediente, terna, destruindo tecidos, rasgando artérias, tendões, até ao fundo, até ao cabo, num movimento inteiro e uno." (HORTA, 1985, p. 63). Essa descrição minuciosa faz do assassínio um acto consciente e da lâmina um instrumento quase cirúrgico que opera no interior do corpo do marido, cortando ligações e desfazendo as estruturas. Trata-se afinal de matar o corpo patriarcal destruindo a organização interna assimilada à organização social que hierarquiza e separa. 
Demais, o gume da lâmina remete para a espada, metáfora usada no livro para designar o sexo do marido durante as relações sexuais: "espada a subir em fogo na sua barriga.” (HORTA, 1985, p. 63). A isotopia da lâmina na carne do outro que penetra ferindo, constantemente retomada, faz com que este episódio enverede a imagem do acto sexual, sendo a repetição uma forma de alcançar o gozo. Opera-se assim, através desta metamorfose, uma inversão dos lugares e das representações. Ema ocupa agora o lugar do marido e não é por acaso que o assassínio acontece no escritório que lhe era até à hora proibido. Porém, Ema não se transformou apenas numa mulher viril. E o assassínio - relação sexual enche-se de ternura enquanto ela observa e sente o corpo do marido:

O seu sangue era morno, morno e espesso com o gosto do ferro do corrimão da escada de caracol das traseiras de casa de meus pais; (...)

Lambi-lhe o sangue da cara, do pescoço, sobre a ferida: lambi-lhe a ferida de lábios escancarados depois de eu ter tirado a faca e a ter limpo muito bem à minha saia.

Poderia dizer que lhe bebi o sangue com o mesmo gozo que D. Pedro sentiu ao comer o Coração do assassino de Inês.

O mesmo orgasmo.

Depois lambi-lhe o peito, entreabri-lhe a camisa e lambi-lhe o peito, desabotoei-lhe as calças, desci-as e lambi-lhe a barriga, os pêlos do púbis. E por fim o pénis murcho, sem vida, sem violência como o de um rapazinho. (HORTA, 1985, p. 97-98)

Depois do assassínio é que o relacionamento pode deveras acontecer através da mediação duma boca quase antropófaga, faminta de preliminares sexuais então banidos pela acutilância da espada. Essa boca é também reveladora de uma sensualidade dos corpos que permite, como já dissemos, a intercoporeidade dos corpos. De resto, esta cena desfaz completamente as categorias estabelecidas. O marido morto, destituído da sua aura paternalista, adquire marcas do feminino e da criança. De facto, o sangue da ferida infligida remete para o sangue menstrual. De igual modo, a ferida é descrita com termos que evocam o sexo feminino e o corpo da mulher: "a ferida de lábios escancarados". Ema reverte, quanto a ela, a imagem de uma vampira, anulando assim os limites entre vida e morte, transpondo ainda a fronteira entre o humano e o inumano porque ela é também a mãe que aconchega e cuida da criança. Ela age portanto num misto de gozo, de ternura e de crueldade, que conduz à desqualificação de toda e qualquer tentativa em determinar definitivamente a sua atitude.

Em conclusão, a demarcação do feminino no romance Ema é o demarcar de um espaço cujas fronteiras nunca são fixas ou estanques; é um espaço sem inscrição que afinal nada tem a ver com um território a 
percorrer, mas sim com o voo das fadas, das bruxas, dos anjos que tanto cantou Maria Teresa Horta. Por isso, a demarcação do feminino leva-nos a repensar os recortes espaciais, e seria profícuo reflectir, nessa obra, sobre a questão do género a partir de uma geografia textual que muito tem a dizer de um corpo, em procura constante de integração ao mundo e ao outro.

\section{REFERÊNCIAS BIBLIOGRÁFICAS}

CIXOUS, Hélène. Le rire de la Méduse. In L’Arc, n. 61, p. 39-54, 1975.

CHEVALIER, Jean e GHEERBRANT, Alain. Dictinnaire des symboles. Paris: $2^{\circ}$ ed. Éditions Robert Laffont S.A. et Éditions Jupiter, 2000.

COLLOT, Michel. Le corps cosmos. Bruxelles: La Lettres Volée, 2008.

HORTA, Maria Teresa. Ema. 2a ed. Lisboa: Edições Rolim, 1985.

. Poesia reunida. Lisboa: Publicações Dom Quixote, 2009.

DERRIDA, Jacques. De la grammatologie. Paris: Editions de Minuit, 1967.

. La loi du genre. In: Parages, Paris: Galilée, p. 249-287, 1986.

IRIGARAY, Luce. Sexe et parentés. Paris: Éditions de Minuit, 1987.

Recebido para publicação em 19/11/2012

Aprovado em 23/02/2013

\section{NOTAS}

1 A “des-marcação" difere da demarcação que é operada pelos maridos das três Ema ao negar-lhes a identidade. Ao invés, a "des-marcação" é empreendida pela(s) Ema(s) para tentar desfazer-se das marcas que as encerram num espaço demarcado, o do patriarcado.

2 Segundo Jean Chevalier e Alain Gheerbrant, a asa é "avant tout symbole d'envol, c'est à dire d'allègement, de dématérialisation, de libération - qu'elle soit de l'âme ou de l'esprit - de passage au corps subtil" (CHEVALIER; GHEERBRANT, 2000, p. 17). As asas são omnipresentes na obra de Maria Teresa Horta, em particular sob a forma do anjo.

$3 \mathrm{Na}$ obra posterior da autora, a travessia das fronteiras é também travessia dos géneros literários. Com efeito, textos como A Paixão segundo Constança H. e As Luzes de Leonor cumprem um deslize constante entre a poesia e a prosa, abarcando vários sub-géneros.

4 Esta vertente "pedagógica” é recorrente na poesia de Maria Teresa Horta, em que o sujeito poético feminino assume o papel de iniciadora. Em Educação sentimental, por exemplo, a aprentisagem do amor implica uma descoberta do corpo do outro e do corpo da mulher. Vd o poema epónimo : "Põe devagar os dedos, devagar...// carrega devagar/ até ao cimo// O suco lento que/ sentes escorregar/ é o suor das grutas/ e seu vinho// Contorna o poço,/ aí tens de parar,/ descer, talvez,/ tomar outro caminho...// Mas põe os dedos e sobe,/ devagar.../ Não tenhas medo/ daquilo que te ensino." (HORTA, 2009, p. 352). 